\title{
Arctic sea ice sensitivity to lateral melting representation in a coupled climate model
}

\author{
Madison Smith ${ }^{1}$, Marika Holland ${ }^{2}$, and Bonnie Light ${ }^{1}$ \\ ${ }^{1}$ Applied Physics Lab, University of Washington, Seattle, Washington, USA \\ ${ }^{2}$ National Center for Atmospheric Research, Boulder, Colorado, USA
}

Correspondence: Madison Smith (mmsmith@uw.edu)

\begin{abstract}
The melting of sea ice floes from the edges (lateral melting) results in open water formation and subsequently increases absorption of solar shortwave energy. However, lateral melt plays a small role in the sea ice mass budget in both hemispheres in most climate models (Keen et al., 2020). This is likely influenced by simple parameterizations of this process in sea ice models that are constrained by limited observations. Here we use a coupled climate model (CESM2.0) to assess the sensitivity of modeled sea ice state to the lateral melt parameterization. The results show that sea ice is sensitive both to the parameters determining the effective lateral melt rate, as well as the nuances in how lateral melting is applied to the ice pack. Increasing the lateral melt rate within the range of reasonable values is largely compensated by decreases in the basal melt rate, but can still result in a significant decrease in sea ice concentration and thickness, particularly in the marginal ice zone. We suggest that it is important to consider the efficiency of melt processes at forming open water, which drives the majority of the ice-albedo feedback. Melt processes are more efficient at forming open water in thinner ice scenarios (as we are likely to see in the future), suggesting the importance of well representing thermodynamic evolution. Revisiting model parameterizations of lateral melting with observations will require finding new ways to represent important physical processes.
\end{abstract}

\section{Introduction}

In both the Arctic and the Antarctic, sea ice forms a heterogeneous cover on the ocean that undergoes strong seasonal changes.

A key factor in the annual retreat of sea ice cover is the sea ice-albedo feedback. This feedback encompasses a variety of changes in ice mass and surface characteristics (such as the melt of snow and formation of melt ponds), but the largest component of this feedback is typically considered to be the loss of ice-covered area to open water area (Curry et al., 1995). The formation of open water is primarily due to thermodynamic melt, but dynamics can also play a significant role in some regions as a result of advection (Rigor et al., 2002).

Throughout the summer, the absorption of solar shortwave radiation promotes ice melt. Absorption at the ice surface causes surface melt, and absorption by the ocean increases ocean heat. Heat in the upper ocean promotes basal and lateral sea ice melt. All three of these melt processes (surface, basal, and lateral) contribute to open water formation by reducing ice volume with varying effects on ice thickness and area. Vertical melt processes (surface and basal) can only form open water once the ice is very thin, while lateral melt can directly form open water area regardless of ice thickness. 

ice-albedo feedback is key to being able to realistically simulate changes (e.g. Holland et al., 2006b). The role of this feedback depends on a variety of model parameterizations and choices. Clearly, the formation of open water is dependent on the representation of melt processes. Additionally, the implementation of these melt processes depends on other choices in the sea ice and ocean models. In particular, the representation of the sea ice cover using an ice thickness distribution results in a stronger albedo feedback because of the impact on thermodynamic processes (Holland et al., 2006a). As a result, climate models including a sea ice component with sub-grid scale ice thickness distributions have best matched observations of sea ice extent over the satellite era (Stroeve et al., 2007). Bitz et al. (2001) states that "resolving thin ice [using the ice thickness distribution] eliminates the need for partitioning an unrealistically high fraction of heat flux toward lateral melt". This indicates both the importance of the ice thickness distribution in simulating melt rates, and also the potential effect of lateral melt on driving feedbacks.

Relatively little work has been done to understand the role of lateral melt in sea ice evolution, with the foundation for much of what is known coming from a few observations made in the 1980's. Perovich (1983) used a dataset of lateral melt at a static lead in the Canadian Arctic to estimate empirical parameters for Josberger and Martin (1981)'s formulation relating temperature of the water above freezing to the melt rate. Later, Maykut and Perovich (1987) suggested another formulation for lateral melting, which included wind friction velocity $\left(u_{*}\right)$, using a somewhat larger set of observations from MIZEX. However, the inclusion of wind friction velocity did not result in significant improvement in fit with observations and is more difficult to constrain, and so was not largely adopted.

Both observations and modeling studies have suggested that it is important to resolve the partitioning of solar energy absorbed in leads and the upper ocean between lateral and basal melting. Maykut and Perovich (1987) used observations from the Greenland Sea to suggest that lead width, orientation, and current velocities drive the relative degree of lateral melting. Steele (1992) used a simple model to assess partitioning of lateral and basal melting in the Arctic given by empirical parameterizations. Steele's study suggests that under the typical Arctic summer forcing, lateral melting is significant only for floes with average diameter on the order of $30 \mathrm{~m}$ or less, while another study suggests that lateral melt is sensitive to floe size with diameters $100 \mathrm{~m}$ or less (Tsamados et al., 2015). Hunke (2014) found that in a coupled climate model, lateral melting may be important, despite being a small term in mass budget, because of the sensitivity of sea ice to thermodynamic processes and the distribution across ice thickness categories. Model experiments showed that although lateral and basal melt are both driven by heat in the ocean, they do not necessarily vary in the same way. Changes in basal or lateral melting, such as related to model resolution, may be compensated by a balancing change in the other term. Skyllingstad et al. (2005) developed an LES model for leads which showed that freshwater stratification in leads plays a major role in controlling lateral melting. It is clear that further field data are required to illuminate the relationships of physical controls with lateral and basal melt rates.

With recent model developments to include floe sizes, there has been renewed interest in the modeling community to properly describe lateral melt (i.e. Roach et al., 2019) as the lateral melt rate has been suggested to be particularly sensitive to the floe size distribution (Bateson et al., 2020). However, sea ice models incorporating floe size (i.e. Bateson et al., 2020) still utilize the empirical relationship for lateral melting introduced by Perovich (1983). There is a notable disconnect in the evolution of 
models to include more complex and realistic physics and the progress of our physical understanding of lateral processes that drive these changes. Bateson et al. (2020) explored the sensitivity of sea ice to higher lateral melting by incorporating a floe size distribution with smaller floe sizes. They found that increased lateral melting was largely compensated for by decreased basal melting in a ice-ocean coupled model, but different results might be expected in a coupled climate model that allows feedbacks related to the formation of open water.

Previous studies have explored the importance of open water for sea ice mean state by using what was defined by Holland et al. (2006b) as the open water formation efficiency: the area of open water formed in a region as a result of a unit reduction in sea ice volume. The mean sea ice thickness and volume are strongly related to the total summer open water formation efficiency in models, as the open water formation is important for sea ice volume evolution (Holland et al., 2006b; Massonnet et al., 2018). The open water formation efficiency has since been used to understand the trajectory of the Arctic towards an icefree summer, indicating the importance of melt processes on the ice-albedo feedback in capturing sea ice response to forcings (i.e. Massonnet et al., 2018; Lindsay et al., 2009; Merryfield et al., 2008). While the efficiency of different melt processes at forming open water has not been explored, we expect that the relative magnitude will play a role in determining the resulting sea ice state.

In the present paper, we modify the lateral melt parameterization in a coupled global climate model, CESM2.0. The main objective of this study is to investigate to what extent lateral melting can affect the simulation of sea ice in a coupled climate model as a result of ice-albedo feedback.

\section{Model and experimental design}

\subsection{CESM2}

Sensitivity tests were done in CESM2.0 (Danabasoglu et al., 2020) using a constant pre-industrial forcing, over a global model domain with nominal horizontal resolution of $1^{\circ}$. The model runs completed here have fully coupled atmosphere, sea ice, and land models, but a simplified slab ocean model (SOM). The SOM replaces the standard full-depth ocean model with a single surface ocean mixed layer with a prescribed depth (Bitz et al., 2012). The surface layer in the ocean model is $10 \mathrm{~m}$, so the prescribed mixed layer depth must be $10 \mathrm{~m}$ or larger. The mixed layer temperature evolves with surface heat fluxes, and has prescribed ocean heat flux associated with advection and mixing that is obtained from the fully coupled CESM2.0 run. Although not specifically constrained in the model, this results in all heat that goes into the mixed layer in ice-covered areas over the annual cycle going back into the atmosphere or the ice. The use of the SOM allows the model to converge must faster (e.g. around 30 years) and so requires significantly less computational time. It has been specifically used to assess climate sensitivity (Bacmeister et al., 2020; Gettelman et al., 2019), as the fully coupled atmosphere permits feedbacks, but dynamic feedbacks between the ocean and sea ice model are limited.

The sea ice model used is CICE version 5.1.2 (Hunke et al., 2015), which uses mushy-layer thermodynamics by default (Turner and Hunke, 2015; Bailey et al., 2020). Other key features include the elastic-viscous-plastic rheology and sub-grid ice thickness distribution, with a default of five categories, included in prior versions (Fig. 1). Sea ice simulated by CESM2.0 over 


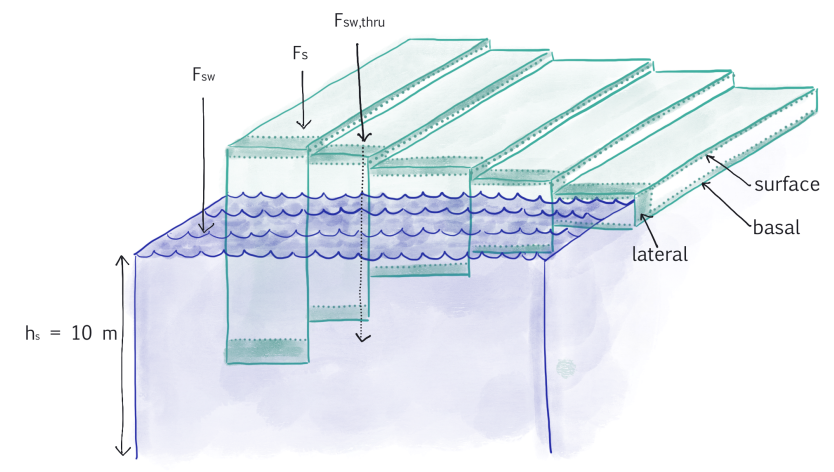

Figure 1. Schematic of key melt processes in CICE sea ice model. Based on schematics from Notz and Bitz (2017); Petty et al. (2014).

the historical period has reasonable mean state and variability in both hemispheres (DeRepentigny et al., 2020). The version used here uses tuned albedos for a more realistic simulation (Kay et al., In prep).

Each run was at least 60 years long, and averages were typically done over the last 25 years. Monthly-averaged outputs are used to examine changes in mean state of the sea ice, while daily averages are required to examine efficiency of melt processes.

\subsubsection{Representation of the ice thickness distribution}

The CICE model includes an ice thickness distribution, which is common across most modern global sea ice models (Keen et al., 2020). Sea ice is discretized into a set number of categories, which occupy an evolving fraction of the grid cell. Sea ice volume and area are transferred between categories as a result of sea ice melt and growth, as well as dynamic processes. Lipscomb (2001) introduced a linear remapping scheme to transfer ice between categories, which has faster convergence and is less diffusive than prior schemes.

Based on the results of Bitz et al. (2001), a majority of global climate models with a sea ice component use five thickness categories as the default (Keen et al., 2020), where are all assumed equally in contact with open water (Fig. 1). Runs in a coupled climate model showed that this number struck a balance of capturing the features of runs with higher numbers of categories, while still keeping computational load low. However, there are a number of different schemes for determining the boundaries of the discretized ice thickness categories. The original discretization scheme, used here, follows the definition of category boundaries from Lipscomb (2001) (Eq. 22) which gives more widely spaced boundaries for thicker ice. The higher resolution for thin ice is beneficial to minimize diffusion, as well as to better resolve the evolving mass budget. The mass budget has a non-linear sensitivity to ice thickness because of the inverse relationship with congelation growth (where thick ice grows slowly and thin ice grows rapidly). 


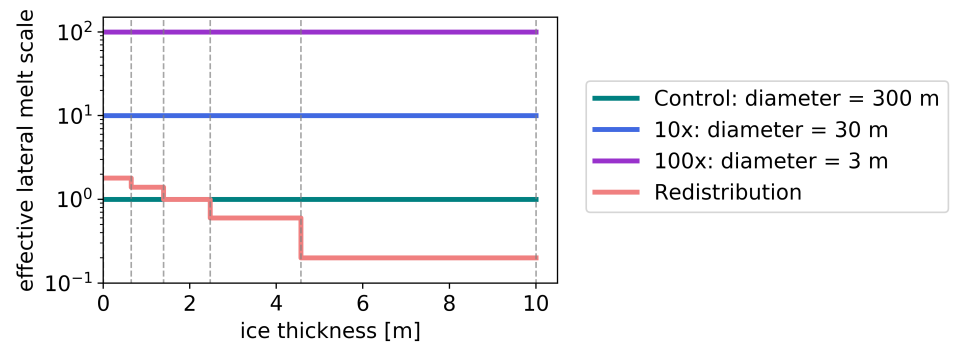

Figure 2. Summary of lateral melt rates for all sensitivity runs. Vertical dashed grey lines indicates bounds of the 5 ice thickness distribution categories (ncat). Solid lines show the effective lateral melt rate scale, relative to a value of 1 for the default parameterization. Decreasing the floe size $D$ and increasing the scale $r_{n}$ have the same effect, such that the effective lateral melt rate scale can be summarized as $\frac{r_{n}}{D / 300}$, where 300 is default floe diameter.

\subsubsection{Parameterization of lateral melting}

The lateral melt rate is determined based on an empirical relationship with the difference of the sea surface temperature (SST) from freezing $(\Delta T)$ giving a uniform melt rate around the perimeter of the floe:

where the constants are based on empirical estimates from Perovich (1983), $m_{1}=1.6 \times 10^{-6}$ (units $\mathrm{m} \mathrm{s}^{-1} \mathrm{deg}^{-m_{2}}$ ), and $m_{2}=1.36$ (unitless).

This is then used to calculate the change in ice concentration $(a)$ for each thickness category as a result of lateral melt

$\left(\frac{d a}{d t}\right)_{l a t, n}=\frac{w_{l a t} * d t * \pi}{\alpha * D}$

over a given time-step, $d t$ (Steele, 1992). Effective floe diameter (D) is a constant value of $300 \mathrm{~m}$ by default, that does not evolve with melting. $\alpha$ is a floe shape parameter representing the non-circularity of floes set at a default of 0.66 (Rothrock and Thorndike, 1984). Note that $\left(\frac{d a}{d t}\right)_{l a t, n}$ is referred to as $r_{\text {side }}$ in the model.

Finally, the lateral melt rate, $(d V / d t)_{l a t}$, is calculated as

$\left(\frac{d V}{d t}\right)_{l a t}=\sum_{n} V_{i c e, n}\left(\frac{d a}{d t}\right)_{l a t, n}$

The temperature of the surface ocean (i.e. $\Delta T$ ) is also used to determine the basal turbulent heat exchange driving basal melt, in additional to lateral melt. The sum of ocean flux terms is not allowed to exceed the heat content in the ocean surface layer. If it does, reductions are made to the lateral and basal melt rates by a constant factor.

\subsection{Sensitivity experiments}

The control run uses default parameterizations of lateral melting as described above (i.e. floe diameter $=300 \mathrm{~m}$ ), and was run using a constant pre-industrial forcing for sixty years. Three experiments of 60-year duration were performed with the model. 
To test the impact of increased lateral melting, we completed two runs where the constant floe diameter $D$ was decreased to 30 $\mathrm{m}$ and $3 \mathrm{~m}$, which effectively increases the lateral melt rate by 10 and 100 times. Other parameters controlling the rate of lateral melting as a function of temperature difference, $m_{1}$ and $m_{2}$, were kept the same, but it is noted that the effect of increasing $m_{1}$ is the same as decreasing the diameter $D$ (Fig. 2).

For the control and increased lateral melt rate (10x and 100x) runs, Eq. 3 suggests that lateral melt occurs equally in all thickness categories such that all decrease by the same percent each time step. However, we can imagine a number of physical reasons why lateral melt rate might be unequally distributed across the ice thickness categories, including: (i) the possibility that the upper ocean is stratified as a result of heating during the melt season (i.e. Holland, 2003), (ii) the potential for a relationship between ice thickness and floe size, (iii) cases where the open water area (leads) that result in lateral melting are unequally distributed across the ice thicknesses. While we can not yet explicitly test the impact of these processes in the model, we can explore the impact of the non-uniform lateral melt they may result in. We test the sensitivity of the model to the distribution of lateral melting by increasing the melt rate in thin classes and decreasing it in thick classes. Eq. 3 is altered to include an ITD re-distribution factor $\left(r_{n}\right)$ over the $n$ ice categories:

$\left(\frac{d V}{d t}\right)_{l a t}=\sum_{n} V_{i c e, n}\left(\frac{d a}{d t}\right)_{l a t, n} r_{n}$

with arbitrarily defined $r_{n}=[1.8,1.4,1.0,0.6,0.2]$. These values were distributed around 1 with the aim of keeping the total lateral melt volume approximately the same, such that the effect of the redistribution can be uniquely observed. Note that the category-dependent melt values were only saved for the last 5 years of this run, and so average open water formation efficiency values (see section 2.3) are only over this period, compared to the last 25 years for other runs. The results are qualitatively unchanged by averaging over 5 years for all runs (not shown).

The schematic in Fig 2 summarizes the effective changes to lateral melt rate in each of these runs compared to the control. The changes to the effective lateral melt rate scale are larger for the 10x and 100x runs (blue and purple, respectively) than for the redistribution run (light red), but remain evenly applied across all thickness distribution categories (delineated by the grey dashed lines).

\subsection{Open water formation efficiency of melt processes}

We build off the definitions of open water formation efficiency (OWFE) used by Holland et al. (2006b) and Massonnet et al. (2018) to define OWFE for individual melt processes as a ratio of the associated area of open water formed $(d a / d t)$ and the volume of sea ice melt $(d V / d t)$ (e.g. the area of open water formed per volume melted):

OWFE $=\frac{d a / d t}{d V / d t}$

This permits the examination of the contribution of melt processes to the albedo feedback, regardless of the total volume of melt that they currently result in in the model. We look only at grid cells from daily outputs with non-zero melt rates and zero total growth rates in order to isolate the influence of melt processes. The OWFE of lateral melt is specifically defined as

$\mathrm{OWFE}_{l a t}=\frac{(d a / d t)_{l a t}}{(d V / d t)_{l a t}}$ 
https://doi.org/10.5194/tc-2021-67

Preprint. Discussion started: 5 March 2021

(c) Author(s) 2021. CC BY 4.0 License.

(c) (i)

In general, the calculation of change in concentration from lateral melt is calculated as

$\sum_{n}\left(\frac{d a}{d t}\right)_{l a t, n}=\sum_{n}\left(\frac{d V}{d t}\right)_{l a t, n} \frac{1}{V_{i c e, n} r_{n}}$

where $n$ is number of ice thickness categories.

With the default model configurations, where lateral melt as defined in Eq. 3 is applied to all thickness categories equally, this simplifies to

$\mathrm{OWFE}_{l a t}=\frac{1}{V_{\text {ice }}}$

Thus, the area of open water formed from lateral melting is directly proportional to average ice thickness in the grid cell in control and sensitivity runs with increased lateral melt rate. For the run with lateral melt redistribution, the OWFE of lateral melt will additionally include the redistribution factor:

$\mathrm{OWFE}_{l a t}=\frac{\sum_{n}\left[(d V / d t)_{l a t, n} \cdot V_{i c e, n}^{-1} r_{n}^{-1}\right]}{(d V / d t)_{l a t}}$

Vertical melt is a result of both basal and surface melt. The efficiency of vertical melt processes $\left(\mathrm{OWFE}_{\text {vert }}\right)$ is calculated using the difference between the total change in concentration due to thermodynamic processes (output daily from the model as $\left.(d a / d t)_{\text {thermo }}\right)$ and the change in concentration due to lateral melt

$\left(\frac{d a}{d t}\right)_{\text {vert }}=\left(\frac{d a}{d t}\right)_{\text {thermo }}-\left(\frac{d a}{d t}\right)_{l a t}$

The open water formation efficiency of vertical processes is then

$\mathrm{OWFE}_{v e r t}=\frac{(d a / d t)_{v e r t}}{(d V / d t)_{b a s a l}+(d V / d t)_{t o p}}$

The schematic in Figure 1 illustrates how the OWFE of melt processes is related to the ice thickness distribution. Lateral melting rate is applied to all categories equally. While thin ice categories will melt most rapidly, open water forms equally in all categories such that the OWFE of lateral melt should be directly tied to the average thickness. In contrast, vertical melt rates are determined by the balance of fluxes and so are unevenly distributed across the categories. However, open water formation is driven by ice in the thinnest categories, as vertical melt results in open water formation only when a portion of ice completely melts through.

\section{Results}

\subsection{Changes in ice concentration and thickness}

Figure 3 shows the seasonal cycle of sea ice area, volume, average thickness, average concentration (calculated as the ratio of sea ice area to extent), and thick ice area in the Northern Hemisphere with a constant pre-industrial forcing. As is convention, 

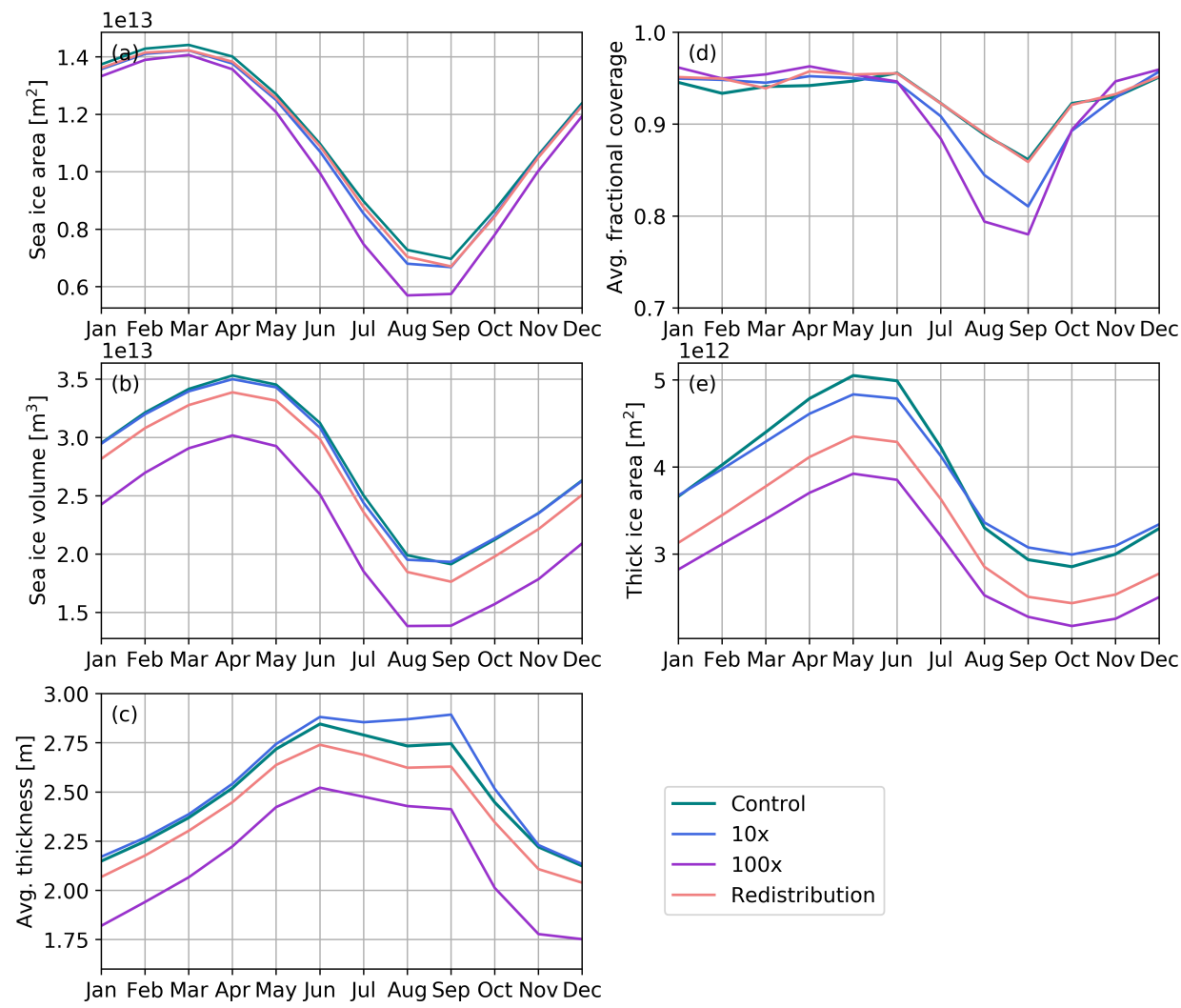

Figure 3. Seasonal cycle of Northern Hemisphere (a) sea ice area $\left(\mathrm{m}^{2}\right)$, (b) sea ice volume $\left(\mathrm{m}^{3}\right)$, (c) average sea ice thickness (m), (d) average fraction of sea-ice covered area, calculated as ratio of sea ice area to sea ice extent, and (e) area with thick ice (greater than $2.5 \mathrm{~m}$ ) for all sensitivity runs with pre-Industrial forcing - control run (teal), 10x lateral melt run (blue), 100x lateral melt run (purple), and redistributed lateral melt (light red).

hemispheric sea ice area and volume are the sums of individual grid-cell areas and volumes, respectively, and extent is the sum of grid cell areas where concentration exceeds $15 \%$. The control run shows the expected maxima in area in March and volume in April, while the minima for both occur in September.

The most notable effect on sea ice state in sensitivity runs is that increasing the lateral melt rate reduces sea ice volume (Fig. $3 b)$. However, there is a minor response to the 10x increase in lateral melting, while the 100x increase drastically reduces sea ice volume (by approximately $5 \mathrm{e} 12 \mathrm{~m}^{3}$ during all months), and moderately reduces sea ice area (Fig. 3a). In fact, the average thickness is somewhat higher July to October in the 10x run compared to the control, while it is significantly reduced in the 100x run (Fig. 3c). Redistribution of lateral melt to thin categories reduces the sea ice volume across all months. Contrary to intuition, increasing the lateral melt does not necessarily reduce sea ice area and volume.

The ratio of sea ice area to sea ice extent is approximately equal to the average sea ice concentration (Fig. 3d). All runs are between 0.9 and 1 from November to June, but are lower during the summer melt season, suggesting more open water in the 


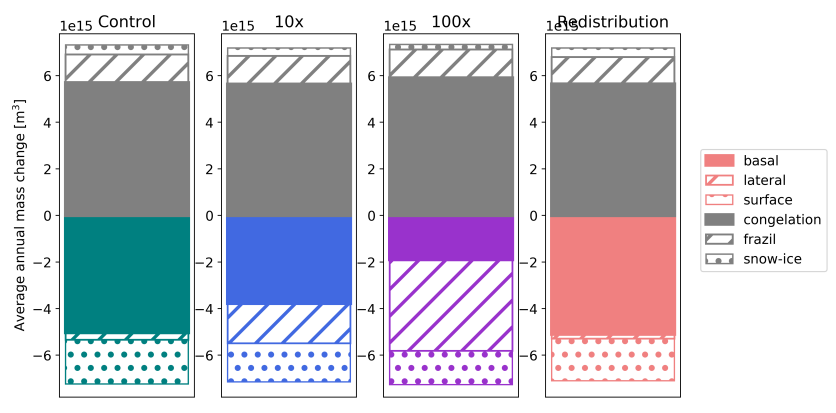

Figure 4. Annual Northern Hemisphere mass budgets for all sensitivity runs (from left to right: control, 10x lateral melt, 100x lateral melt, redistributed lateral melt). Grey areas represent volume of growth terms - congelation (solid), frazil (hashed), and snow-ice (dotted) - and colored areas represent volumes of melt terms - basal (solid), lateral (hashed), and surface (dotted).

ice-covered areas during this time. While the control and redistribution runs reach a minimum of about 0.86 , both the $10 \mathrm{x}$ and 100x reach significantly lower, with minimums of 0.81 and 0.78 respectively. This suggests more potential for atmosphereocean interactions in ice-covered areas when the lateral melt rate is higher. Increasing the lateral melt rate primarily reduces the sea ice concentration around the margins, where the sea ice is relatively thin and low concentrations. For example, there is a substantial decline ( $20-30 \%$ in July) in Hudson Bay. Here, the ice is relatively thin and formation of open water can drive albedo feedback.

\subsection{Changes in mass budget}

The average volume of sea ice grown and melted annually is comparable across all runs (as shown by mass budgets in Figure 4). This agrees with the consistent amplitude of the sea ice volume seasonal cycle seen in Fig $3 \mathrm{~b}$. This is because the increase in total lateral melting (when lateral melt rate is increased) is largely compensated by a decrease in basal melting, such that the change in total sea ice melted is small. Both lateral and basal melting are driven by heat in the upper layer of the ocean model. As there is a finite amount of heat available in this layer, increasing the heat used for lateral melting reduces the heat available for basal melting. More rapid lateral melt increases the total melt rate early in the season, when more heat is available, but decreases it later in the summer as more heat has already been used for melting and solar insolation is lower. We note that although the total melt remains near constant because of the compensating effect of basal melt, the melt is distributed heterogeneously across thicknesses by design and likely leads to the resulting changes in sea ice mean state, as will be discussed further in the next section.

Although there is a similar magnitude change in the volume of lateral melt from the control run to the 10x and 100x sensitivity runs (Fig. 4), there is a significantly more drastic decrease in sea ice area and volume in the 100x lateral melt run compared to the 10x lateral melt run (Fig. 3). This suggests that the ice-albedo feedback from lateral melting is initially small, such that the increase associated with the 10x run results in little change in total sea ice. As the lateral melt rate becomes much 


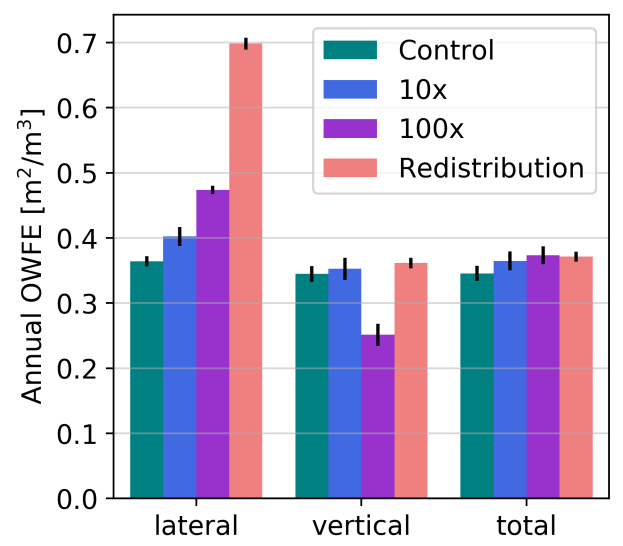

Figure 5. Open water formation efficiency (OWFE) for lateral melt, vertical melt processes, and as annual total for all sensitivity runs. Colored bars show the 25-year mean, with control run in teal, 10x lateral melt run in blue, 100x lateral melt run in purple, and redistributed lateral melt in light red. Black lines denote standard deviation.

larger, there is more open water formed in ice covered areas over the melt season (Fig. 3c) and the ice-albedo feedback is significant enough to result in substantial changes in sea ice mean state.

The portion of the mass budget accounted for by lateral melting is decreased in the lateral melt redistribution run, despite the intention to keep the total lateral melt approximately the same. This may be a side effect of the adjustments to the lateral melt parameterization; the redistribution results in more rapid melt of thin ice, but also results in less thin ice to melt. The seasonal cycle of the mass budget (not shown) shows that total melt is in fact increased early in the melt season, but approximately unchanged in mid-late summer.

\subsection{Open water formation efficiencies}

In Fig. 5, we examine the total annual open water formation efficiency, as defined by Eq. 5, as well as the efficiency specifically of lateral and vertical melt processes, as defined by Eqns. 9 and 11. In the control run, the total open water efficiency is on average $0.35 \mathrm{~m}^{2} / \mathrm{m}^{3}$, suggesting an average of $0.35 \mathrm{~m}^{2}$ open water formed for every cubic meter of ice melted, with similar values of 0.37 and $0.34 \mathrm{~m}^{2} / \mathrm{m}^{3}$ for specifically lateral and vertical melt processes.

When the lateral melt rate is increased, it not only comprises a larger portion of the total ice volume melted (Fig. 4), but also forms open water more efficiently for the same volume melted (Fig. 5). The OWFE of lateral melting is more drastically increased for the $100 \mathrm{x}$, to $0.47 \mathrm{~m}^{2} / \mathrm{m}^{3}$. As the lateral melt OWFE is closely tied to the average sea ice thickness, it is clear to see that this is a result of the thinner ice and reduction in thick ice area (Fig. 3c,e). However, it is less clear why there is still an increase in lateral OWFE for the 10x run, where average sea ice thickness is actually higher. Here, the importance of thick ice in different melt processes is underscored. The thick ice area in the 10x lateral melt run is lower than in the control run, 
https://doi.org/10.5194/tc-2021-67

Preprint. Discussion started: 5 March 2021

(c) Author(s) 2021. CC BY 4.0 License.

(c) (1)

especially during the peak of the melt season (Fig. 3e). This results in an increase in the fraction of moderate thickness ice, in

the range at which lateral melting is relatively efficient at forming open water.

The OWFE of vertical melting is significantly reduced to $0.25 \mathrm{~m}^{2} / \mathrm{m}^{3}$ for the $100 \mathrm{x}$ run because lateral melting more efficiently removes the thin ice. Vertical melting can only form open water from the thinnest ice categories, while lateral melting can form open water in any ice category while heat remains in the ocean. Interestingly, the vertical melting efficiency only decreases in the 100x sensitivity run. There is essentially no change in fractional or absolute area of the thinnest ice category in 10x run, while it is significantly reduced throughout the summer melt season for 100x run (not shown). Less ice in the thinnest thickness category means that there is less opportunity for vertical melt processes to form open water.

Interestingly, the total OWFE remains approximately constant across all sensitivity runs. This is most surprising for the 100x lateral melt run, where we may expect a higher total OWFE as a result of thinner ice on average. Massonnet et al. (2018) showed that across a range of climate models, runs with less ice volume have higher OWFE. (Though, it is worth noting that their definition of OWFE varies from that used here in that it is defined as the linear fit between annual summer area loss and volume loss, such that it may be more related to inter-annual variability.) This suggests that for a single model, the mean state of the sea ice is more a result of the distribution of thermodynamic processes, rather than just the total OWFE. Altering the lateral melt parameterization changes the open water formation in a way that is not fully reflected in the average thickness or sea ice mass budget.

Redistributing lateral melt towards thin categories results in large increases in OWFE of lateral melting as thin ice is more rapidly converted to open water (Fig. 5), but the vertical and total OWFE remain essentially unchanged. Both of these are a result of changes in the distribution of ice thickness. Basal melt transitions sea ice between categories, while lateral melt does not, such that an unintended consequence of reducing lateral melt in the thick categories is increasing basal melt in these categories. This results in overall less thick ice (Fig. 3e). So, the lateral OWFE increases in the redistribution sensitivity run not only because the alterations to the parameterization form open water more efficiently, but also because there is thinner ice on average, which inherently forms open water from lateral melting more efficiently. However, changes to average thickness are not substantial enough to impact the efficiency of vertical melt processes.

\subsubsection{Timing of OWFE}

As the solar shortwave energy reaching the surface in the Arctic peaks in June, the distribution of open water formation over time has an impact on the sea ice state. More efficient open water formation early in the summer is likely to result in a stronger ice-albedo feedback. In the control run, the OWFE of vertical melt processes generally peaks early in the summer, when ice is on average thinner due to the inclusion of thin first-year ice in the marginal ice zone (Fig. 6). The OWFE of lateral melt remains high throughout the melt season, and is higher than vertical melt after June 1.

The changes in basin-averaged sea ice thickness in Fig. $6 \mathrm{~b}$ delineate two melt regimes that correspond to the temporal importance of melt processes. From April until early June, the average thickness over the entire Northern Hemisphere ice pack is increasing. This indicates that mass loss is dominated by the melt of thin ice. In mid-June, the average thickness begins decreasing, as little thin ice remains and primarily thick ice is being melted. (The decrease in average thickness in the latter 

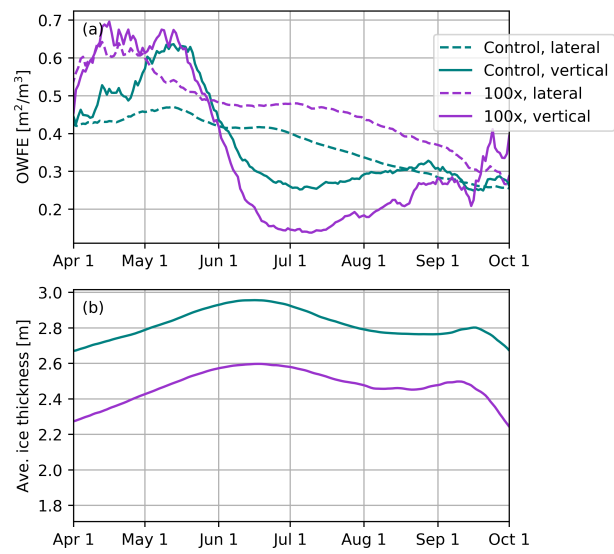

Figure 6. Daily (a) OWFE of lateral and vertical melt and (b) average sea ice thickness over the Northern Hemisphere over the melt season. Results are shown for control and 100x lateral melt runs only (teal and purple, respectively).

half of September is a result of the beginning of new thin ice formation.) These regimes correspond with changes in OWFE; vertical melt OWFE is high primarily when melting of thin ice dominates. Lateral melt OWFE remains high when melting is primarily thick ice, all the way through until September. It is worth noting here that mass loss from both vertical and lateral melt have a similar temporal distribution, and vertical melting accounts for significantly more volume than lateral melting in the control run (Fig. 4). This result simply indicates that lateral melting that occurs during this period results in proportionally more open water formation than does the vertical melting.

The shapes are generally similar for all sensitivity runs, though the magnitudes are shifted (100x run only is shown in Fig. 6 , for simplicity). Higher lateral melt rates result in lateral melt having higher OWFE throughout the entire melt seasonal. The OWFE of vertical melt is lower particularly from June onwards, when the mass loss is dominated by the melt of thicker ice.

\section{Discussion}

\subsection{Sensitivity in the Southern Hemisphere}

Here, we have focused on the sensitivity of modeled Arctic sea ice thickness and volume to lateral melting parameterizations. The majority of observations of lateral melting have been made in the Arctic, where the sea ice area and volume are undergoing the most drastic changes. We expect the sensitivity to melt parameterizations to be somewhat different in the Southern Hemisphere, where sea ice is typically thinner and more seasonal, and there is more ocean heat availability.

Fig. 7 shows the seasonal cycle of sea ice area and volume in the Southern Hemisphere. Sea ice area and volume are significantly lower year-round for all sensitivity runs. In particular, the area and volume of sea ice is approximately $50 \%$ lower during the summer months in the 100x lateral melt rate run compared to the control. The relative reductions in the 10x and 100x runs indicate a more linear response of sea ice to the lateral melt rate compared to the Arctic. Here, the 10x lateral melt 


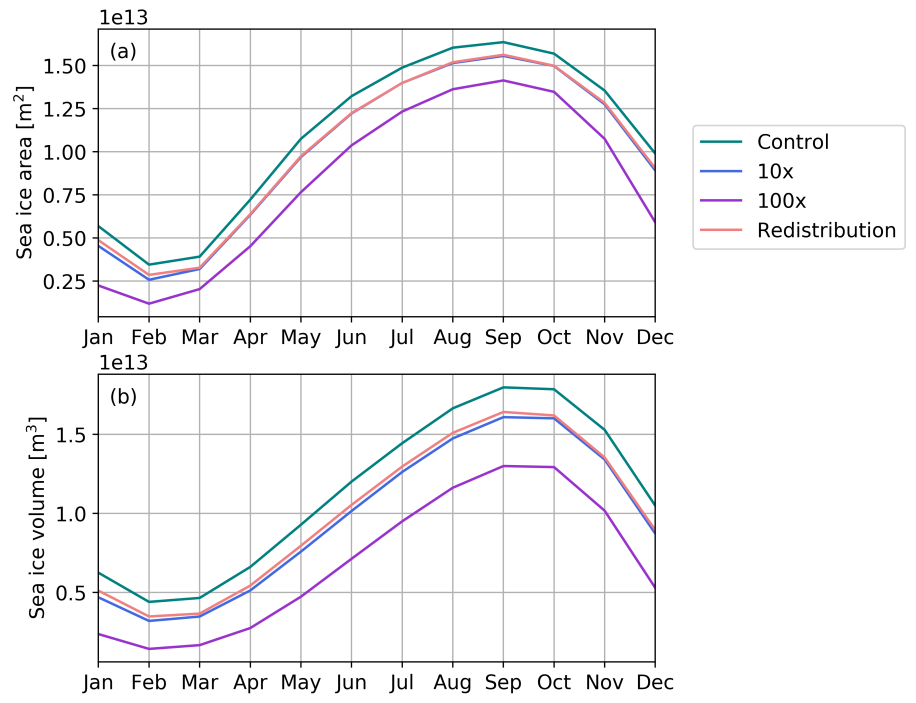

Figure 7. Seasonal cycle of Southern Hemisphere (a) sea ice area $\left(\mathrm{m}^{2}\right)$ and (b) sea ice volume $\left(\mathrm{m}^{3}\right)$ for all sensitivity runs with pre-Industrial forcing - control run (teal), 10x lateral melt run (blue), 100x lateral melt run (purple), and redistributed lateral melt (light red).

and redistribution runs result in nearly the same reduction in sea ice area and volume. The redistribution of lateral melt to thin ice categories has an even larger impact than in the Arctic, likely due to the larger proportion of thin ice. It is still notable that redistribution results in a comparable decrease in ice to the 10x run, despite negligible change in the lateral melt (Fig 8).

As in the Arctic, the increase in total lateral melt in the Southern Hemisphere sea ice results in a decrease in total basal melt (Fig 8). However, the total melt in the mass budgets here are lower when lateral melt is increased and there is less ice (Fig. 7b), whereas the total melt volume remained comparable across runs in the Arctic (Fig. 3b). The limiting factor in total melt in the Southern Hemisphere is likely the amount of sea ice, rather than the available heat in the ocean. Increasing the lateral melt rate results in similar rates of heat flux from the ocean to the ice in most areas of the Antarctic, but over the smaller resulting ice-covered area (not shown). In contrast, in the Arctic, increasing lateral melt 100x increases the rates of heat flux from the ocean to the ice in the summer, but over a smaller area. The limiting factor in melt in the Arctic Ocean is the available ocean heat, and the reduction in ice area compensates for the increased ice-ocean heat flux to result in a similar total annual melt.

The OWFE of lateral melting in the Antarctic is higher early in the melt season, when open water contributes to larger ice-albedo feedback (Fig. 9). The OWFE of vertical melting for the control run peaks in early January, when it becomes more efficient than lateral melting. During this period, the thin ice is melting more rapidly and the average thickness of the ice is increasing. The OWFE of lateral melting and vertical melting diverge more strongly in the 100x run (magenta lines in Fig. 9). Here, lateral melting has a higher efficiency at forming open water than vertical melting through nearly the entirety of the melt season. As the average ice thickness peaks in mid-February, and the average ice thickness begins to decline due to the formation of new ice in some regions, the vertical melt OWFE increases again. Similar shapes are seen across the other runs, and indicate a larger potential role of lateral melting in the seasonal Antarctic ice pack. Here, ice-albedo feedback is not 


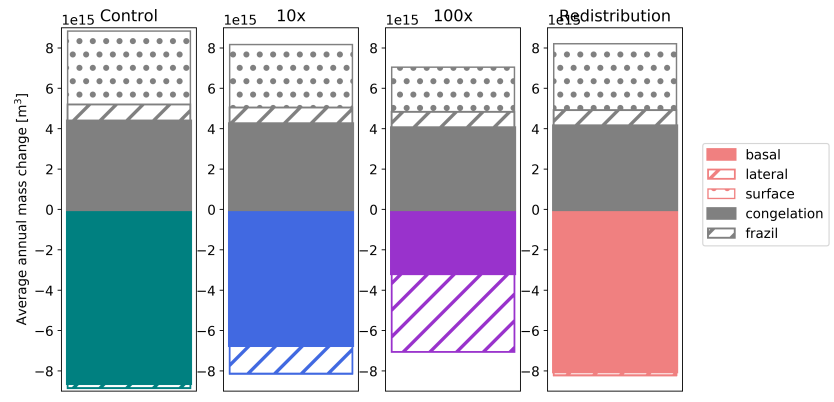

Figure 8. Annual Southern Hemisphere mass budgets for all sensitivity runs (from left to right: control, 10x lateral melt, 100x lateral melt, redistributed lateral melt). Grey areas represent volume of growth terms - congelation (solid), frazil (hashed), and snow-ice (dotted) - and colored areas represent volumes of melt terms - basal (solid), lateral (hashed), and surface (dotted).
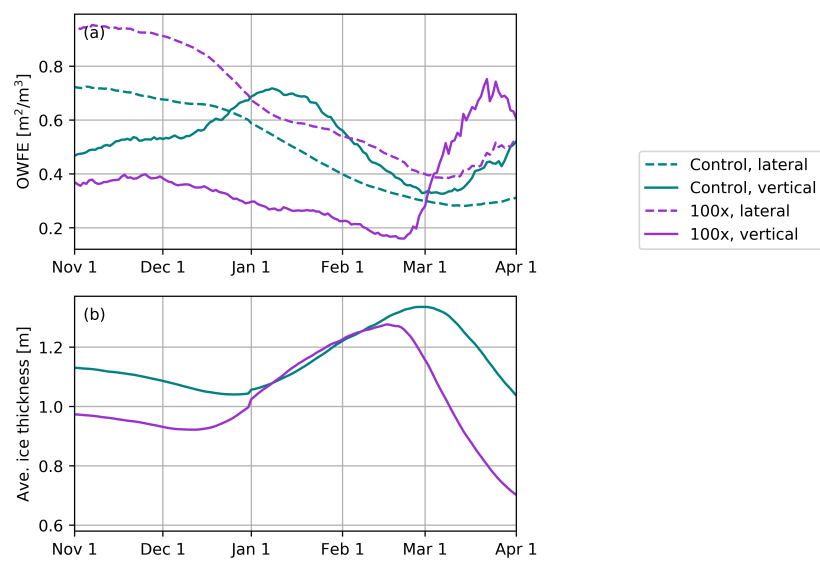

Figure 9. Daily (a) OWFE of lateral and vertical melt and (b) basin-averaged sea ice thickness in the Southern Hemisphere over the melt season. Results are shown for control and 100x lateral melt runs only (teal and purple, respectively).

the main reason for why increasing lateral melting results in lower sea ice mean state. Although the absorption of shortwave radiation is likely a secondary factor in the reduction of sea ice, it is likely to play a role in delaying the ice growth during freeze-up. The differences observed in the role of lateral melting in the Antarctic compared to the Arctic may be indicative of what we might expect to see for Arctic sea ice in the future, when an ice-free summer is common and sea ice is even more seasonal.

\subsection{Sensitivity in a $2 \mathrm{xCO}_{2}$ scenario}

We expect melt processes to be different in other climate conditions with less overall sea ice, particularly in the Arctic where there is more often multi-year ice. We completed sensitivity runs with control and 100x lateral melt rate settings in a $2 \mathrm{xCO}_{2}$ scenario. This forcing abruptly doubles atmospheric carbon dioxide and is run to steady state. Both the control and 100x runs 

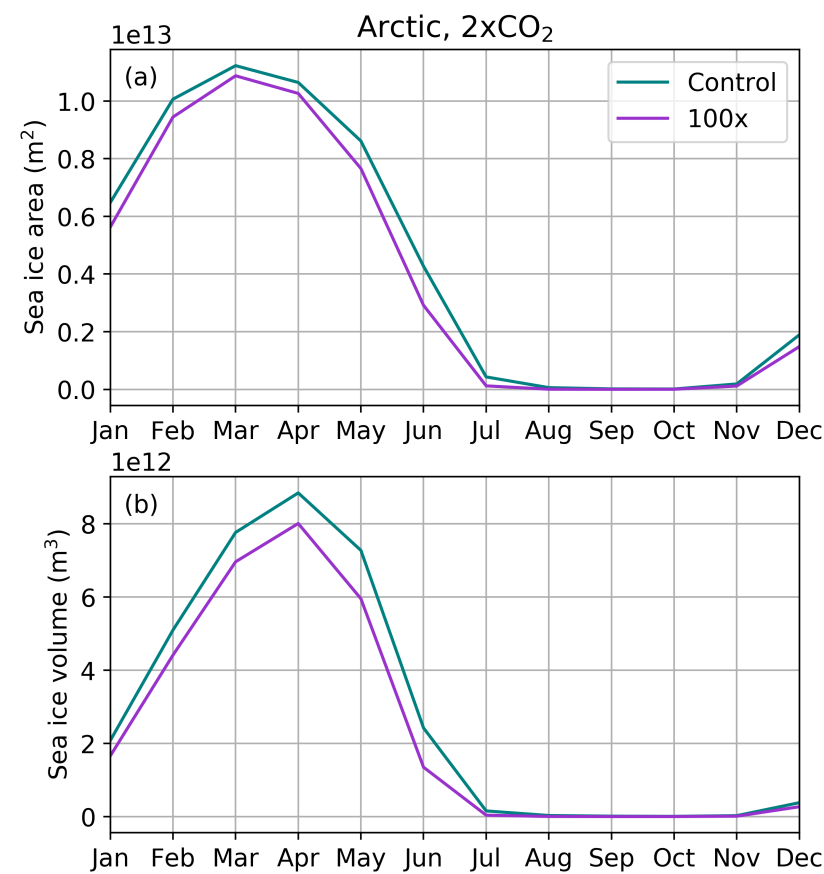

Figure 10. Seasonal cycle of Northern Hemisphere (a) sea ice area $\left(\mathrm{m}^{2}\right)$, (b) sea ice volume $\left(\mathrm{m}^{3}\right)$ with $2 \mathrm{xCO}_{2}$ forcing - control run (teal), and 100x lateral melt run (purple).

experience an "ice-free summer", with effectively no sea ice from July through October (Fig. 10). There is less total and percent change from increasing the lateral melt 100x, as the sea ice is already substantially less extensive and thinner. Maximum sea ice area similarly occurs in March, but is approximately 50\% lower than in pre-industrial conditions. Most notably, the increased lateral melt rate steepens the decline to ice-free summer conditions during the melt season (Fig. 10).

Both total and process OWFEs are significantly higher for both runs; while total OWFE was below 0.4 for all pre-industrial runs, it is approximately 0.8 for both in the $2 \mathrm{xCO}_{2}$ runs (Fig. 11a). Separating it out into lateral and vertical melt shows that the 100x lateral melt rate significantly increases the OWFE of lateral melt and decreases the OWFE of vertical melt processes. Interestingly, the OWFE is higher for vertical melt than lateral for the control run. The low average ice thickness allows vertical melt processes to be very efficient at forming open water, and so lateral melt is relatively inefficient.

In $2 \mathrm{xCO}_{2}$ runs, lateral melt dominates open water formation early in the summer (regardless of the lateral melt rate). OWFE of vertical melt peaks just before the Arctic becomes essentially ice-free, when ice is very thin (Fig. 11b). The difference between lateral and vertical melt during early summer melt is enhanced by increased lateral melt rates. This suggests that in thinner ice scenarios, lateral melt is more critical to open water formation feedbacks driving ice-free Arctic conditions. 

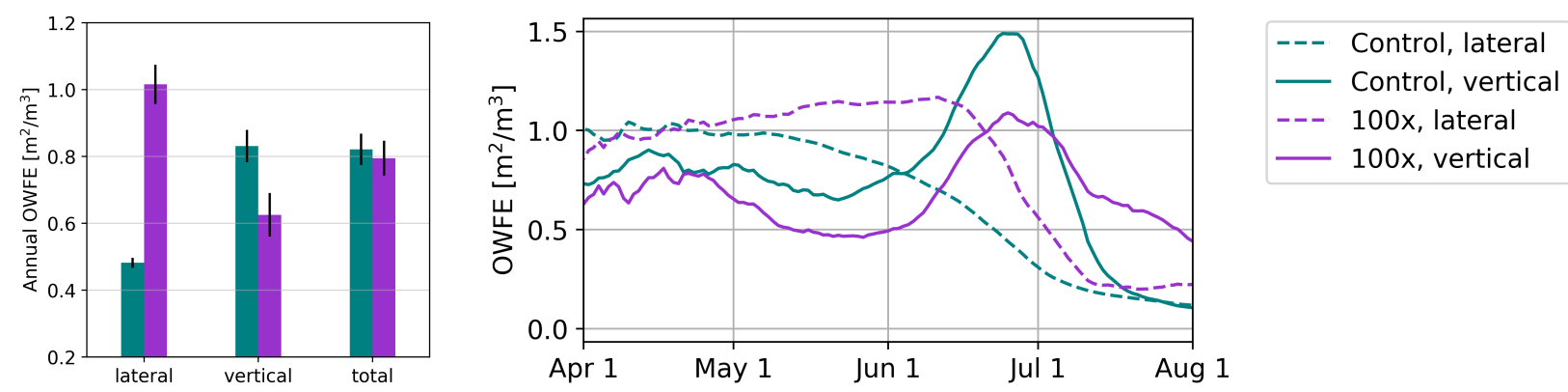

Figure 11. Open water formation efficiency (OWFE) in the Northern Hemisphere for $2 \mathrm{xCO}_{2}$ forcing runs. (left) Annual average OWFE for lateral melt, vertical melt processes, and total melt. Colored bars show the 25-year mean, with control run in teal, 10x lateral melt run in blue, 100x lateral melt run in purple, and redistributed lateral melt in light red. Black lines denote standard deviation. (right) Daily OWFE throughout the Arctic melt season of lateral melt (dashed lines) and vertical melt (solid lines) for control and 100x lateral melt runs (teal, and purple, respectively).

\subsection{Role of the ITD}

Though realistic values of OWFE have not been established, we suggest that one factor contributing to why we don't see a large change in sea ice with initial increases in lateral melt rates in the model (i.e. 10x run) is because of the representation of the ice thickness distribution. The ITD in CICE uses a linear remapping scheme to move ice melted (and grown) between categories (Lipscomb, 2001). As a result, melting in the thinnest category generally results in the formation of some open water, even from basal and surface melt. Thus, the model's representation of ice thickness may contribute to vertical melt being relatively efficient at forming open water (and thus having a high OWFE).

The details of the ITD, including the linear remapping scheme and the number and bounds of thickness categories, are likely to have an impact on melt efficiency and thus the ice mean state. Prior studies have investigated the impact of the number of ITD categories in climate models with sea ice coupled to the ocean (Ungermann et al., 2017; Massonnet et al., 2019; MorenoChamarro et al., in review, 2019; Bitz et al., 2001). Their results generally suggested no clear benefit from increasing the number of categories beyond 5, and that representation of thick ice categories has most impact on the representation of Arctic ice in the current climate. However, we might expect that the resolution of thin ice categories will have more impact in a fully coupled climate model, where ice-albedo feedbacks are likely more realistic as the atmosphere can respond to changes in the ocean and sea ice. More work to understand the role of the number of ITD categories and remapping scheme in a fully-coupled context is needed. Particularly, it will be informative to investigate how the ITD controls feedbacks related to melt processes. 


\section{Conclusions}

We have assessed the sensitivity of sea ice to the lateral melting parameterization in a coupled climate model. Our results confirm the importance of a physically based parameterization for lateral melting through a few key conclusions:

- Increased lateral melt rates increase the efficiency of lateral melting at forming open water, which decreases local ice concentrations during the summer. Because of the interconnected nature of lateral and basal melting, this does not uniformly result in less ice. At high lateral melt rates, the ice-albedo feedback results in a notably thinner and less extensive Arctic ice cover.

- The details of how lateral melting is represented and distributed matter. The assumption that lateral melting occurs at the same rate across all ice thicknesses is particularly called into question. Higher lateral melt rates (or smaller floes) in areas of thin ice reduces sea ice volume in both hemispheres.

- While the lateral melt may play a relatively small role in the mass budget, these results suggest that this does not tell the full story of how sea ice evolves thermodynamically. Lateral melt can have an impact on the mean state due to its role in open water formation and the ice-albedo feedback.

As the results suggest that nuances of parameterizations can impact the sea ice state, we encourage revisiting model representations of how ocean heat drives sea ice melt using observations. Other factors beyond those currently included are likely to be important. Modeling work (Skyllingstad et al., 2005) has suggested that lead width and wind speed are likely important to melt rates. Forthcoming observations from MOSAiC and other summer field campaigns will be useful to better constrain the controls on melt processes. For example, Richter-Menge et al. (2001) presented observations from the SHEBA campaign in 1998 that showed the accumulation of significant heat content in the upper meter of the lead. This led to accelerated lateral melt, and rapid basal melt associated with the delayed mixing of this layer. We saw a similar evolution in leads during the summer on the MOSAiC expedition in 2020, with a warmer and fresher layer on the order of $10 \mathrm{~cm}$ to $1 \mathrm{~m}$ thick spanning more than a month during the melt season. This suggests that small-scale stratification is a common occurrence in summer leads that should be considered in modeling. Currently, the $10 \mathrm{~m}$ ocean surface layer in CESM2 prevents simulating the nuances of how much heat is captured specifically in leads. One possible way forward is to explicitly represent aspects of leads within the sea ice component of the model, such that finer-scale processes can be represented.

Another potentially important simplification in the model representation is that it assumes a uniform distribution of vertical and lateral melt locally, as sea ice is represented as a rectangle for thermodynamic and radiative transfer calculations (Fig. 1). In reality, lateral melt rates are often higher near the surface, resulting in a sub-surface shelf. The formation of the shelf, which appears light like a melt pond (e.g. Perovich et al., 2003, Fig. 13), results in a higher albedo locally and likely reduced heat accumulation. In addition, the results suggest that basal and lateral melt rates are closely linked. It could be important to resolve uncertainties in basal melt transfer coefficients, which is beyond the scope of the current sensitivity study. Revisiting lateral melt parameterizations will require finding new ways to capture the important physical controls. 
https://doi.org/10.5194/tc-2021-67

Preprint. Discussion started: 5 March 2021

(c) Author(s) 2021. CC BY 4.0 License.

(c) (i)

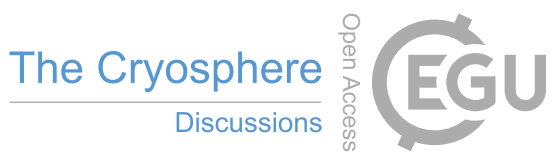

While we do not specifically address here what the correct rate of lateral melting should be, model experiments by Roach et al. (2019) suggest that effective floe diameters as low as $3 \mathrm{~m}$ may be realistic through much of the Arctic MIZ, where lateral melt is greatest. Lateral melt rate representation relies on other parameters in addition to floe size, but clearly physically realistic floe size distributions are an important first step in simulating more realistic melt distribution. For example, it will be possible to explicitly represent the relationship of thickness and floe size in CICE using the joint floe size-thickness distribution developed by Roach et al. (2018) fully coupled with wave, atmosphere, and ocean models. There are a number of additional efforts currently underway to include floe size distributions in sea ice models (Zhang et al., 2015; Horvat and Tziperman, 2015; Roach et al., 2018). Thus, the redistribution of lateral melt towards thinner categories as tested in this study may be able to be explicitly represented in future versions of the model.

390 Author contributions. MH and BL developed the concept and obtained funding for this work. MS and MH designed and ran experiments. MS led preparation of the manuscript, with feedback from MH and BL.

Competing interests. The authors declare that no competing interests are present.

Acknowledgements. This research was supported by NSF grants 1724467 and 172474 . The CESM project is supported primarily by the National Science Foundation. Computing and data storage resources, including the Cheyenne supercomputer (https:// doi.org/10.5065/ D6RX99HX), were provided by the Computational and Information Systems Laboratory (CISL) at NCAR. We thank all the scientists, software engineers, and administrators who contributed to the development of CESM2. We wish to acknowledge Dave Bailey for assistance with setting up runs and processing outputs. 
https://doi.org/10.5194/tc-2021-67

Preprint. Discussion started: 5 March 2021

(c) Author(s) 2021. CC BY 4.0 License.

(c) (i)

\section{References}

Bacmeister, J., Hannay, C., Medeiros, B., Gettelman, A., Neale, R., Fredriksen, H., Lipscomb, W., Simpson, I., Bailey, D., Holland, M., et al.: CO 2 Increase Experiments Using the CESM: Relationship to Climate Sensitivity and Comparison of CESM1 to CESM2, Journal of Advances in Modeling Earth Systems, 12, e2020MS002 120, 2020.

Bailey, D. A., Holland, M. M., DuVivier, A. K., Hunke, E. C., and Turner, A. K.: Impact of a New Sea Ice Thermodynamic Formulation in the CESM2 sea ice component, Journal of Advances in Modeling Earth Systems, 12, e2020MS002 154, 2020.

Bateson, A. W., Feltham, D. L., Schröder, D., Hosekova, L., Ridley, J. K., and Aksenov, Y.: Impact of sea ice floe size distribution on seasonal fragmentation and melt of Arctic sea ice, The Cryosphere, 14, 403-428, 2020.

Bitz, C., Holland, M., Weaver, A., and Eby, M.: Simulating the ice-thickness distribution in a coupled climate model, Journal of Geophysical Research: Oceans, 106, 2441-2463, 2001.

Bitz, C. M., Shell, K., Gent, P., Bailey, D., Danabasoglu, G., Armour, K., Holland, M., and Kiehl, J.: Climate sensitivity of the community climate system model, version 4, Journal of Climate, 25, 3053-3070, 2012.

410 Curry, J. A., Schramm, J. L., and Ebert, E. E.: Sea ice-albedo climate feedback mechanism, Journal of Climate, 8, 240-247, 1995.

Danabasoglu, G., Lamarque, J.-F., Bacmeister, J., Bailey, D., DuVivier, A., Edwards, J., Emmons, L., Fasullo, J., Garcia, R., Gettelman, A., et al.: The Community Earth System Model version 2 (CESM2), Journal of Advances in Modeling Earth Systems, 12, e2019MS001 916, 2020.

DeRepentigny, P., Jahn, A., Holland, M. M., and Smith, A.: Arctic sea ice in two configurations of the CESM2 during the 20 th and 21 st centuries, Journal of Geophysical Research: Oceans, 125, e2020JC016 133, 2020.

Gettelman, A., Hannay, C., Bacmeister, J., Neale, R., Pendergrass, A., Danabasoglu, G., Lamarque, J.-F., Fasullo, J., Bailey, D., Lawrence, D., et al.: High climate sensitivity in the Community Earth System Model version 2 (CESM2), Geophysical Research Letters, 46, 8329-8337, 2019.

Holland, M. M.: An improved single-column model representation of ocean mixing associated with summertime leads: Results from a SHEBA case study, Journal of Geophysical Research: Oceans, 108, 2003.

Holland, M. M., Bitz, C. M., Hunke, E. C., Lipscomb, W. H., and Schramm, J. L.: Influence of the sea ice thickness distribution on polar climate in CCSM3, Journal of Climate, 19, 2398-2414, 2006a.

Holland, M. M., Bitz, C. M., and Tremblay, B.: Future abrupt reductions in the summer Arctic sea ice, Geophysical Research Letters, 33, $2006 \mathrm{~b}$.

425 Horvat, C. and Tziperman, E.: A prognostic model of the sea-ice floe size and thickness distribution, Cryosphere, 9, 2119-2134, https://doi.org/10.5194/tc-9-2119-2015, http://www.the-cryosphere.net/9/2119/2015/, 2015.

Hunke, E. C.: Sea ice volume and age: Sensitivity to physical parameterizations and thickness resolution in the CICE sea ice model, Ocean Modelling, 82, 45-59, 2014.

Hunke, E. C., Lipscomb, W. H., Turner, A. K., Jeffery, N., and Elliott, S.: CICE: the Los Alamos Sea Ice Model Documentation and Software

Josberger, E. G. and Martin, S.: A laboratory and theoretical study of the boundary layer adjacent to a vertical melting ice wall in salt water, Journal of Fluid Mechanics, 111, 439-473, 1981. 
https://doi.org/10.5194/tc-2021-67

Preprint. Discussion started: 5 March 2021

(c) Author(s) 2021. CC BY 4.0 License.

(c) (i)

Kay, J. E., DeRepentigny, P., Holland, M., Bailey, D., DuVivier, A., Blanchard-Wrigglesworth, E., Deser, C., Jahn, A., Singh, H., Smith, M., and Webster, M.: The influence of sea ice mean state on climate change and variability in the Community Earth System Model version 2 , To be submitted to JAMES, In prep.

Keen, A., Blockley, E., Bailey, D., Boldingh Debernard, J., Bushuk, M., Delhaye, S., Docquier, D., Feltham, D., Massonnet, F., O’Farrell, S., et al.: An inter-comparison of the mass budget of the Arctic sea ice in CMIP6 models, The Cryosphere Discussions, pp. 1-39, 2020.

Lindsay, R., Zhang, J., Schweiger, A., Steele, M., and Stern, H.: Arctic sea ice retreat in 2007 follows thinning trend, Journal of Climate, 22, 165-176, 2009.

Lipscomb, W. H.: Remapping the thickness distribution in sea ice models, Journal of Geophysical Research: Oceans, 106, 13989-14000, 2001.

Massonnet, F., Vancoppenolle, M., Goosse, H., Docquier, D., Fichefet, T., and Blanchard-Wrigglesworth, E.: Arctic sea-ice change tied to its mean state through thermodynamic processes, Nature Climate Change, 8, 599-603, 2018.

Massonnet, F., Barthélemy, A., Worou, K., Fichefet, T., Vancoppenolle, M., Rousset, C., and Moreno-Chamarro, E.: On the discretization of the ice thickness distribution in the NEMO3. 6-LIM3 global ocean-sea ice model, Geoscientific Model Development, 12, 3745-3758, 2019.

Maykut, G. A. and Perovich, D. K.: The role of shortwave radiation in the summer decay of a sea ice cover, J. Geophys. Res. Ocean., 92, 7032-7044, https://doi.org/10.1029/JC092iC07p07032, http://dx.doi.org/10.1029/JC092iC07p07032, 1987.

Merryfield, W. J., Holland, M. M., and Monahan, A. H.: Multiple equilibria and abrupt transitions in Arctic summer sea ice extent, Arctic Sea Ice Decline: Observations, Projections, Mechanisms, and Implications, Geophys. Monogr. Ser, 180, 151-174, 2008.

Moreno-Chamarro, E., Ortega, P., and Massonnet, F.: Impact of the ice thickness distribution discretization on the sea ice concentration variability in the NEMO3. 6-LIM3 global ocean-sea ice model, Geosci. Model Dev. Discuss., in review, 2019.

Notz, D. and Bitz, C. M.: Sea ice in Earth system models, Sea ice, 3, 304-325, 2017.

Perovich, D.: On the summer decay of a sea ice cover, Ph.D. thesis, University of Washington, Seattle, 1983.

Perovich, D. K., Grenfell, T. C., Richter-Menge, J. A., Light, B., Tucker, W. B., and Eicken, H.: Thin and thinner: Sea ice mass balance measurements during SHEBA, Journal of Geophysical Research: Oceans, 108, 2003.

Petty, A. A., Holland, P. R., and Feltham, D. L.: Sea ice and the ocean mixed layer over the Antarctic shelf seas, The Cryosphere, 8, 761-783, 2014.

Richter-Menge, J. A., Perovich, D. K., and Pegau, W. S.: Summer ice dynamics during SHEBA and its effect on the ocean heat content, Annals of Glaciology, 33, 201-206, 2001.

Rigor, I. G., Wallace, J. M., and Colony, R. L.: Response of sea ice to the Arctic Oscillation, Journal of Climate, 15, $2648-2663,2002$.

Roach, L., Horvat, C., Dean, S. M., and Bitz, C. M.: An emergent sea ice floe size distribution in a global coupled ocean - sea ice model, J. Geophys. Res. Ocean., 2018.

Roach, L. A., Bitz, C. M., Horvat, C., and Dean, S. M.: Advances in Modeling Interactions Between Sea Ice and Ocean Surface Waves, Journal of Advances in Modeling Earth Systems, 2019.

Rothrock, D. A. and Thorndike, A. S.: Measuring the sea ice floe size distribution, J. Geophys. Res. Ocean., 89, 6477-6486, https://doi.org/10.1029/JC089iC04p06477, 1984.

Skyllingstad, E. D., Paulson, C. A., and Pegau, W. S.: Simulation of turbulent exchange processes in summertime leads, Journal of Geophysical Research: Oceans, 110, 2005. 
https://doi.org/10.5194/tc-2021-67

Preprint. Discussion started: 5 March 2021

(c) Author(s) 2021. CC BY 4.0 License.

(c) (i)

470 Steele, M.: Sea ice melting and floe geometry in a simple ice-ocean model, Journal of Geophysical Research: Oceans, 97, 17 729-17 738, 1992.

Stroeve, J., Holland, M. M., Meier, W., Scambos, T., and Serreze, M.: Arctic sea ice decline: Faster than forecast, Geophysical research letters, 34, 2007.

Tsamados, M., Feltham, D., Petty, A., Schroeder, D., and Flocco, D.: Processes controlling surface, bottom and lateral melt of Arctic sea ice

475 in a state of the art sea ice model, Philosophical Transactions of the Royal Society A: Mathematical, Physical and Engineering Sciences, 373, $20140167,2015$.

Turner, A. K. and Hunke, E. C.: Impacts of a mushy-layer thermodynamic approach in global sea-ice simulations using the CICE sea-ice model, Journal of Geophysical Research: Oceans, 120, 1253-1275, 2015.

Ungermann, M., Tremblay, L. B., Martin, T., and Losch, M.: Impact of the ice strength formulation on the performance of a sea ice thickness distribution model in the A rctic, Journal of Geophysical Research: Oceans, 122, 2090-2107, 2017.

Zhang, J., Schweiger, A., Steele, M., and Stern, H.: Sea ice floe size distribution in the marginal ice zone: Theory and numerical experiments, J. Geophys. Res. Ocean., 120, 3484-3498, https://doi.org/10.1002/2015JC010770, http://doi.wiley.com/10.1002/2015JC010770, 2015. 